\title{
Role of the emergency extra-intracranial bypass in acute occlusive arterial disease: evidence in the literature as to the benefit to young patients and an illustrative case of a patient with extra- and intracranial traumatic internal carotid artery occlusion
}

\author{
Juan Antonio Castro-Flores ${ }^{1}$, Carlos Eduardo Roelke', Luis Fernando Falcão ${ }^{3}$, Rodrigo Becco de \\ Souza ${ }^{4}$, Tae Yoon Moon ${ }^{5}$, Raimundo Santos ${ }^{6}$, Guilherme Brasileiro de Aguiar', Bruno Nóbrega ${ }^{8}$
}

Hospital São Camilo (Santana), Hospital das Clínicas da Faculdade de Medicina da Universidade de São Paulo (HCFMUSP), Escola Paulista de Medicina da Universidade Federal de São Paulo (Unifesp/EPM) e da Irmandade da Santa Casa de Misericórdia de São Paulo (ISCMSP), São Paulo, SP, Brasil.

\section{ABSTRACT}

The extra-intracranial bypass has been used in the treatment of patients with chronic cerebrovascular insufficiency. More recent studies have demonstrated the benefit of this technique to patients with arterial occlusion in the acute phase. We relate the case of a 19-year-old patient, victim of cervical trauma, who presented evidence of intra- and extracranial internal carotid artery (ICA) occlusion and progressive intra hospital clinical worsening. He underwent a high-flow bypass surgery with NIHSS at 17, progressing with progressive intra hospital improvement and in the outpatient segment achieved a NIHSS of 2 in 6 months of follow-up. We discuss the role of high-and low-flow bypass in chronic occlusive arterial disease, based on a review of the literature. We conclude that in spite of there being a divergence as to the indication for, and benefits of, these techniques in chronic occlusive arterial disease, in the acute phase, there appears to be a more evident benefit mainly in the young patients, whose etiology is the dissection of the ICA.

\section{KEYWORDS}

Brain, cerebral revascularization, stroke, aneurism dissecting.

\section{RESUMO}

Anastomose extraintracraniana de emergência na doença arterial oclusiva aguda: evidências na literatura quanto ao benefício para pacientes jovens e caso ilustrativo de um paciente com oclusão traumática da artéria carótida interna

A anastomose extraintracraniana tem sido utilizada no tratamento de pacientes com insuficiência vascular cerebral crônica. Estudos mais recentes têm demonstrado os benefícios dessa técnica para pacientes com doença arterial oclusiva em sua fase aguda. Relatamos o caso de um jovem de 19 anos, vítima de trauma cervical fechado, que apresentou oclusão da artéria carótida interna $(A C l)$ extra e intracraniana, evoluindo com piora neurológica progressiva. Foi submetido a anastomose de alto fluxo em fase aguda, evoluindo com melhora neurológica, progredindo de um NIHSS de 17 para NIHSS de 2 no seguimento após seis meses. Discutimos, ainda, o papel da anastomose de alto e baixo fluxo na doença arterial oclusiva crônica, com base em revisão da literatura. Concluímos que, embora haja divergência na indicação e nos possíveis benefícios, as técnicas de anastomoses podem proporcionar maior benefício para pacientes jovens, cuja principal etiologia é a dissecção arterial.

\section{PALAVRAS-CHAVE}

Encéfalo, revascularização cerebral, acidente vascular cerebral, aneurisma dissecante.

1 Neurosurgeon, Hospital São Camilo (Santana) and Hospital das Clínicas da Faculdade de Medicina da Universidade de São Paulo (HCFMUSP), São Paulo, SP, Brazil.

2 Neurosurgeon, Hospital São Camilo (Santana) and Hospital dos Servidores Públicos do Estado de São Paulo (HSPE-SP), São Paulo, SP, Brazil.

3 Anesthetist, Hospital São Camilo (Santana) and Escola Paulista de Medicina da Universidade Federal de São Paulo (Unifesp/EPM), São Paulo, SP, Brazil.

4 Resident in Neurosurgery, Irmandade da Santa Casa de Misericórdia de São Paulo (ISCMSP), São Paulo, SP, Brazil.

5 Vascular Surgeon, Hospital São Camilo (Santana) and Unifesp/EPM, São Paulo, SP, Brazil.

6 Vascular Surgeon, Hospital São Camilo (Santana), São Paulo, SP, Brazil.

7 Neurosurgeon, Department of Neurosurgery, ISCMSP, São Paulo, SP, Brazil.

8 Radiologist, Hospital São Camilo (Santana), São Paulo, SP, Brazil. 


\section{Introduction}

The extra-intracranial bypass has been used in the treatment of patients with chronic cerebrovascular insufficiency for whom medicative treatment was not effective. ${ }^{1,2}$ These patients have a borderline cerebral blood flow and present transitory ischemic attacks (TIA) or strokes at the risk sites when submitted to greater hemodynamic stress. ${ }^{1,2}$ The efficacy of revascularization in this population remains controversial, in spite of the good surgical results. ${ }^{1,-5}$ Thus, even with a low rate of neurosurgical complications and a high rate of patency in the bypasses implanted, the groups submitted solely to clinical treatment progress with ischemic events rates statistically similar to those of the surgical groups. For this reason, there is a necessity for better studies to establish the indication of this procedure for patients with chronic arterial insufficiency. ${ }^{6}$

There are reports in the literature of stroke treatment in the acute phase with low-flow bypass, ${ }^{2,7}$ as well as with high-flow. ${ }^{7,8}$ The two studies demonstrate excellent results during the follow-up, constituting a good indication for both surgical techniques. We report on a case, illustrated with radiological and intraoperative images, in which a high-flow bypass was performed in the acute phase of an ischemic event in a patient who was the victim of carotid traumatic dissection. We also made a review of the literature on the utilization of high- and low-flow bypass in the treatment of ischemic stroke.

\section{Case report}

The patient was male, 19 years old, who had been submitted to a strangulation hold while practicing jiu-jitsu, after which he presented a transitory loss of consciousness. Upon awakening, he presented a motor deficit in the left hemibody. He was taken to the emergency room, where he arrived one and a half hours after the event. He was conscious in the initial evaluation, but showed psychomotor agitation and left hemiplegia.

He was submitted to a cranial computerized tomography (CT) with angiotomography, in which there were observable signs of occlusion in the middle cerebral artery (MCA) to the right (Figure 1 A-D), with a "cord sign" already evident in the CT without contrast (Figure 1A) and absence of flow in M1 (Figure 1B) and cortical branches of the middle cerebral artery following the angiotomography exam (Figure 1C). Magnetic resonance imaging (MRI) of the brain was performed, in which an extensive site with altered perfusion in the territory of the carotid and right MCA was observed (Figure 1D).
After performing the aforementioned imaging exams, the patient presented neurological worsening, with a decreased consciousness level. At this moment, three hours after the ictus, he presented a Glasgow Coma Scale of 12 (Motor $=4$, Verbal $=5$, Eye Opening $=3$ ) and NIHSS of 17 . Taking into account the angiotomography and brain MRI findings, following which the diagnosis of extensive thrombus in the internal carotid and right middle arteries was considered, a high-flow bypass was opted for in order to preserve the penumbra area. In this situation, with such an extensive dissection site, a possible endovascular intervention becomes unviable, making the bypass the only viable alternative.

The procedure was initiated with a cervicotomy to expose the common external and internal carotid arteries. Simultaneously, a safenectomy was performed by a vascular surgery team. A right parietal frontotemporal decompressive craniectomy and opening of the Sylvian fissure were performed, upon which the right internal carotid arteries and branch $\mathrm{M} 1$ of the right MCA were visibly thrombosed (Figure 2A). The right frontal branch of the MCA was also thrombosed, however the filling of the temporal branch of the MCA was observed, possibly by anastomoses with collaterals (Figure 2A).

The longitudinal sectioning of the frontal branch of the right middle cerebral artery, with the removal of the blood clots at this site, for the suturing of the saphenous end-to-side graft with 10-0 nylon, was opted for. Following the proximal suturing of this MCA site and, distally, of the external carotid artery, end to end, also with nylon 10-0, an alteration in the coloring of the occluded arteries was observed, representing evidence of graft patency flow (Figure 2B). The bone flap was stored in the abdominal cavity. The surgery began 3 hours following the ictus and lasted a total of 4.5 hours.

The patient progressed to better strength in the left lower limb, reaching stage III on the twelfth postoperatory Day. Due to the absence of cerebral swelling established by the skull control CT, an early cranioplasty was performed on the thirteenth day following the first procedure. The post-operatory cerebral angiotomography showed patent bypass flow (Figure 3 ), as in the cortical regions, representing maintenance of vitality in the penumbra area.

The patient maintained good progression following his release from the hospital, returning on the $29^{\text {th }}$ postoperatory day already ambulating with assistance and presenting with stage II strength in the left upper member. In the $8^{\text {th }}$ post-operatory month, the patient walks without assistance, presenting with stage III strength in the left upper member and NIHSS of 1. 
A

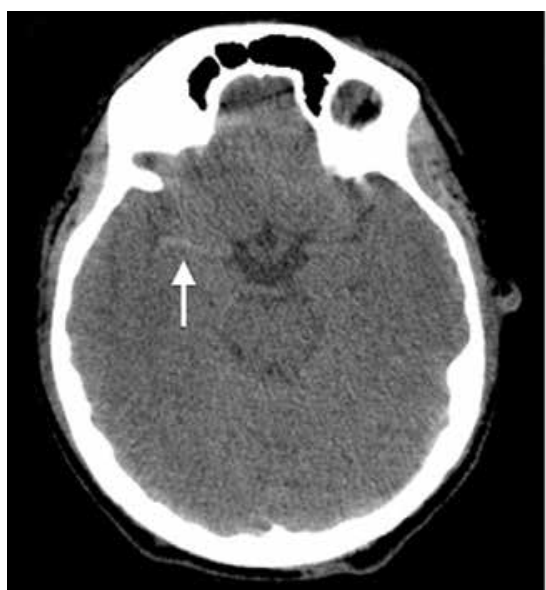

C

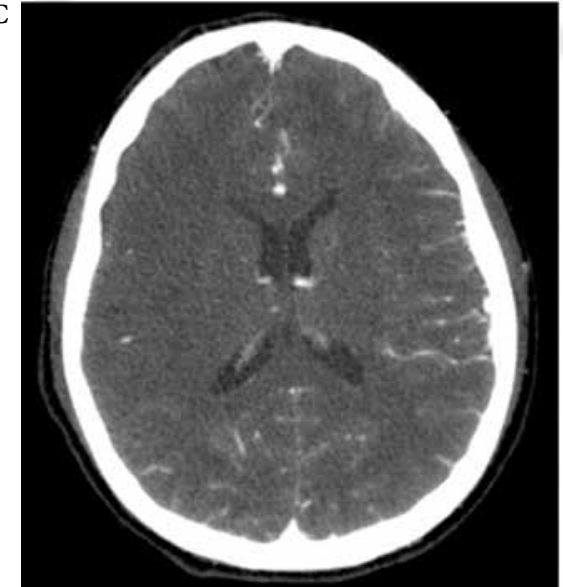

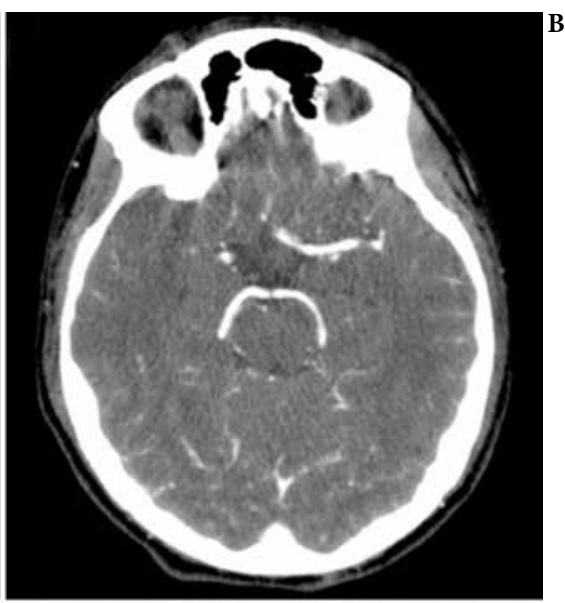

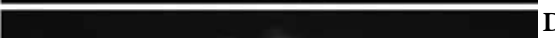

Figure 1 - (A) Cranial CT without contrast showing hyperattenuation of the right MCA ("cord sign" - arrow). (B and C) Angio CT of the brain showing absence of flow in the initial segment of the right MCA and reduction of flow in cortical arteries in the right cerebral hemisphere. (D) Brain MRI showing an alteration in the diffusion in the right MCA territory.

A

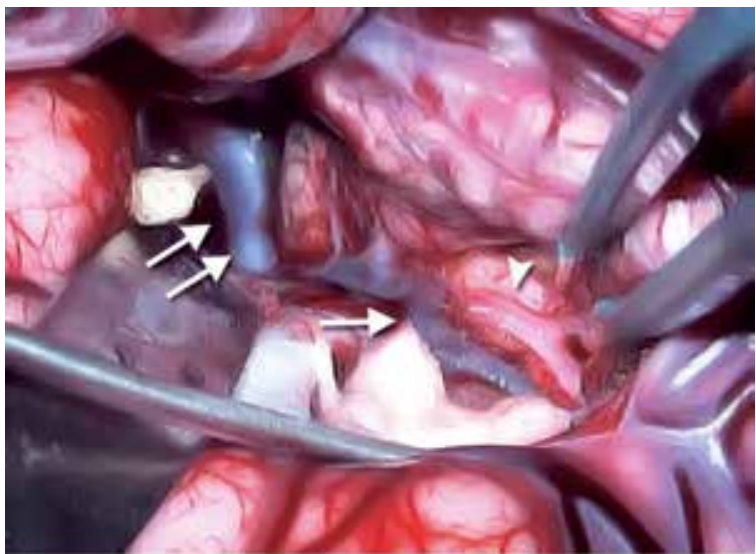

B

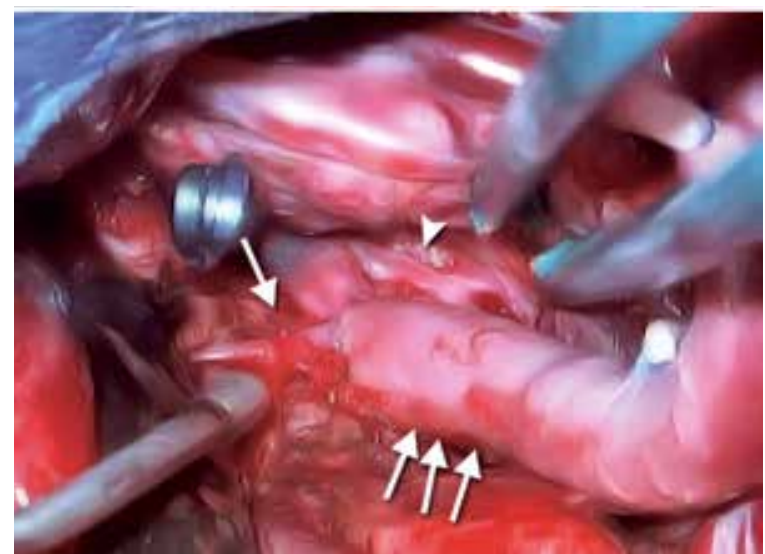

Figure 2 - (A) Double arrow: Thrombosed ICA; arrow: frontal branch of the thrombosed MCA; arrow head: temporal branch of the MCA with filling present. (B) Triple arrow: saphenous graph; arrow head: temporal branch with preserved filling; arrow: frontal branch with preserved filling. 

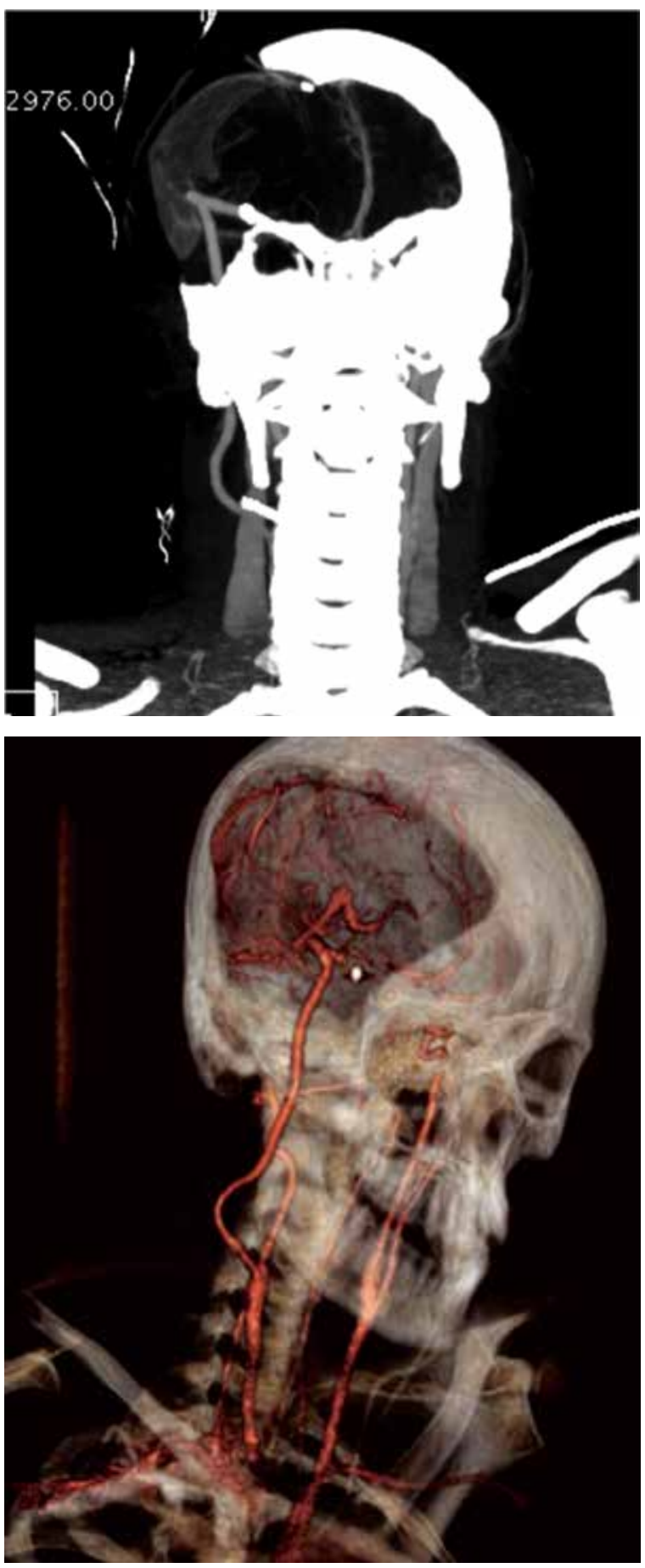

Figure 3 - Patency of bypass showed by angiotomography.

\section{Discussion}

High-flow extra-intracranial bypasses have been performed for diverse indications, such as: necessity for planned sacrifice of the vessel for tumor or intracranial aneurysm treatment, the necessity for planned sacrifice of the vessel reducing the risk of stroke at carotid artery lesions, including post-traumatic and pseudoaneurysm dissections, emergency revascularization for a stroke in progress, and the necessity to increase cerebral blood flow in chronic hemodynamic insufficiency, ${ }^{9}$ and Moyamoya disease. ${ }^{5}$

Independent of the indication, it is necessary to select the patient individually and rigorously before submission to the procedure, especially in cases of chronic occlusive disease. In these cases, the studies have shown important variations in the outcome, since the first large-scale study, the EC-IC bypass study, ${ }^{10}$ performed with 1,377 patients in 1985 . This study concluded that the treatment with a bypass did not reduce the risk of a cerebral ischemic event, as compared to the medical treatment. Much criticism was made, in light of the selection of patients having been based on purely anatomical parameters (cerebral angiography), opening the way for the performance of large-scale studies whose patient selections were based on cerebral physiology.

Among the studies which have utilized cerebral physiology in addition to anatomical parameters, the Japanese EC-IC Bypass Trial (JET) ${ }^{11}$ stands out. It made use of vasoreactivity to acetazolamide (patients with hemodynamic insufficiency have arteries which are at the limit of vasodilation and do not respond to the increase in $\mathrm{CO}_{2}$ induced by acetazolamide) as eligibility criteria for the procedure. This study demonstrated the reduction in ischemic events with the low-flow bypass, which consists in the anastomosis between the superficial temporal artery and the middle cerebral artery (STA-MCA), in relation to the clinical treatment. ${ }^{11}$

The recently published "Carotid Occlusion Surgery Study" (COSS) used, in addition to angiography, the PET to measure the oxygen extraction fraction (OEF) as eligibility criteria. The study demonstrated that the low-flow bypass (STA-MCA) improves, but does not normalize, the $\mathrm{OEF}$ and does not reduce the risk of an ischemic event within 2 years. ${ }^{6}$ A doubt about the COSS is whether the OEF normalization with a high-flow bypass would change the results, in light of the fact that only $25 \%$ of the patients submitted to low-flow bypass present OEF normalization, ${ }^{6}$ the number of patients possibly being insufficient to obtain statistically definitive results.

The contradiction between the COSS and the JET, which both had an excellent surgical result, with less than $5 \%$ of morbid-mortality and more than $95 \%$ of shunt patency, ${ }^{5}$ indicates that it is necessary to further improve the adequacy of the choice of patients for the procedure.

Contrary to the controversial results in relation to the bypass for patients with chronic occlusive disease, we observe more encouraging recent studies on the treatment for acute ischemic events. In 1985, Diaz et al. ${ }^{7}$ 
reported on treatment of 15 stroke patients in the acute phase with normalization of the clinical condition in 10 and partial improvement in 5. A low-flow bypass had been used in 14 cases and only 1 high-flow.

Other authors, namely Morgan and Sekhon, ${ }^{8}$ in 1994, reported on treatment of 6 cases of carotid or vertebral dissection, 4 traumatic and 2 spontaneous, with a high-flow bypass. All of them progressed with a result considered good (three cases) or excellent (three cases). The cases in which the final result was a mild language disorder (the initial symptom being aphasia, hemiplegia and Horner's syndrome), dysarthria (the initial symptom being dizziness and quadriplegia) and those with a significant improvement in the deficits (the initial symptom being hemiplegia and dysphasia) were considered good results; the patients who presented with no deficits following the procedure were considered to have excellent results.

In a 2010 study, Nussbaum et al. ${ }^{2}$ reported on 13 lowflow bypasses (STA-MCA) in 13 patients in the acute phase of an ischemic event, ${ }^{2}$ eleven being dissections and 2, arterial stenosis. In at least ten cases, the imaging exams suggested arterial dissection, and small flow limited to leptomeningeal collateral circulation. The average preoperative NIHSS 11.8 and 3 months after the surgery, 2.5. All cases presented clinical improvement.

We observed that the majority of the 34 patients referred to in the acute-phase bypass procedures ${ }^{2,7,8}$ presented an internal carotid artery (ICA) or vertebral dissection. Bearing in mind that there was no control group, we asked ourselves if the patients would have progressed in the same manner had neurosurgery not been opted for. The best way to answer this question would be with a prospective and randomized study, with the least possible bias. In the absence of this, we are left with the comparison of the progress obtained in the clinical treatment of other studies.

Debette and Leys, ${ }^{12}$ in 2009, related that the proportion of patients who had complete resolution of the arterial abnormalities following clinical treatment varied among the studies, being estimated at approximately $46 \%$ for stenosis, $33 \%$ for occlusions and $12 \%$ for dissecting aneurysms. In addition, they mention a recurrence rate of $0 \%-13.3 \%$ for ischemia in the first year following the ictus and variable mortality of 5\%-23\%. In relation to the functional result, the study reported a good result in $75 \%$ of the cases, thus being beyond the results presented by studies in which bypass had been performed. $2,7,8$

Schwartz et al. ${ }^{13}$ reported that spontaneous recanalization occurred in $58.8 \%$ of the patients with nontraumatic internal carotid artery dissection, being more frequent in women $(\mathrm{p}<0.05)$ and less frequent in cases with completely or almost completely occluded vessels $(\mathrm{p}<0.01)$. Also by the same authors is that partially occlude arteries recanalized practically twice as much as totally occluded vessels. ${ }^{13}$

The use of stents in acute ICA occlusion has also been presented as a therapeutic option. Dalyai et al. ${ }^{14}$ related that of 17 patients with acute arterial occlusion in the cervical ICA, 16 (94\%) presented an immediate improvement in flow, improvement in the average NIHSS, from 16.5 to 4.8 , however with $17 \%$ of mortality. In this study, a NIHSS greater than 6 was among the inclusion criteria, but one of the patients was presented as having an initial NIHSS of four, ${ }^{14}$ and the mortality rate increased to $18.75 \%$ with the exclusion of said patient.

In the present case, a high-flow bypass was opted for in light of the fact that this technique proves to be more efficient to normalize immediately the blood flow and the oxygen supply to cerebral tissue, while the low-flow bypass generally does not normalize the OEF most of the time, even if it may normalize the cerebral flow. ${ }^{6}$ Nevertheless, this should not be a rule, as other authors have performed low-flow bypasses and achieved good results., ${ }^{2,7}$

Our illustrative case represents an open horizon for acute-phase stroke treatment, a situation in which high- and low-flow bypasses have proven to be effective, not only for the prevention of clinical worsening, with protection of the penumbra area, but also for the reversal of the catastrophic initial symptoms. In the majority of the collected cases, the patients had presented traumatic arterial dissection with important stroke symptoms, this group possibly being the most-benefitted target. However, there is a need for larger prospective studies, due to the publication bias (publication more commonly being of positive results) existing in case reports and case series.

The bypass techniques for treating cerebral ischemic events due to chronic arterial occlusive disease or ischemic events still need better studies for patient selection for possibly increased benefits. However, these techniques appear to be quite effective in the acute phase of the stroke, especially in cases of arterial traumatic dissection.

\section{Competing interests}

The authors declare no conflict of interest.

\section{References}

1. Derdeyn CP, Grubb RL Jr, Powers WJ. Indications for cerebral revascularization for patients with atherosclerotic carotid occlusion. Skull Base. 2005;15(1):7-14. 
2. Nussbaum ES, Janjua TM, Defillo A, Lowary JL, Nussbaum LA. Emergency extracranial-intracranial bypass surgery for acute ischemic stroke. J Neurosurg. 2010;112(3):666-73.

3. Sundt TM Jr, Whisnant JP, Fode NC, Piepgras DG, Houser OW. Results, complications, and follow-up of 415 bypass operations for occlusive disease of the carotid system. Mayo Clin Proc. 1985;60(4):230-40.

4. Amin-Hanjani S, Butler WE, Ogilvy CS, Carter BS, Barker FG 2nd. Extracranial-intracranial bypass in the treatment of occlusive cerebrovascular disease and intracranial aneurysms in the United States between 1992 and 2001: a population-based study. J Neurosurg. 2005;103(5):794-804.

5. Rodríguez-Hernández A, Josephson SA, Langer D, Lawton MT. Bypass for the prevention of ischemic stroke. World Neurosurg. 2011;76(Suppl 6):72-9.

6. Grubb RL Jr, Powers WJ, Clarke WR, Videen TO, Adams HP Jr, Derdeyn CP, et al. Surgical results of the carotid occlusion surgery study. J Neurosurg. 2013;118(1):25-33.

7. Diaz FG, Ausman Jl, Mehta B, Dujovny M, de los Reyes RA, Pearce J, et al. Acute cerebral revascularization. J Neurosurg. 1985;63(2):200-9.

8. Morgan MK, Sekhon LH. Extracranial-intracranial saphenous vein bypass for carotid or vertebral artery dissections: a report of six cases. J Neurosurg. 1994;80(2):237-46.

9. Sia SF, Morgan MK. High flow extracranial-to-intracranial brain bypass surgery. J Clin Neurosci. 2013;20(1):1-5.
10. The EC/IC Bypass Study Group. Failure of extracranialintracranial arterial bypass to reduce the risk of ischemic stroke. Results of an international randomized trial. $\mathrm{N} \mathrm{Engl}$ J Med. 1985;313(19):1191-200.

11. Jinnouchi J, Toyoda K, Inoue T, Fujimoto S, Gotoh S, Yasumori K, et al. Changes in brain volume 2 years after extracranial-intracranial bypass surgery: a preliminary subanalysis of the Japanese EC-IC trial. Cerebrovasc Dis. 2006;22(2-3):177-82.

12. Debette S, Leys D. Cervical-artery dissections: predisposing factors, diagnosis, and outcome. Lancet Neurol. 2009;8(7):668-78.

13. Schwartz NE, Vertinsky AT, Hirsch KG, Albers GW. Clinical and radiographic natural history of cervical artery dissections. J Stroke Cerebrovasc Dis. 2009;18(6):416-23.

14. Dalyai RT, Chalouhi N, Singhal S, Jabbour P, Gonzalez LF, Dumont AS, et al. Stent-assisted endovascular recanalization of extracranial internal carotid artery occlusion in acute ischemic stroke. World Neurosurg. 2013;79(1):143-8.

Correspondence address

Juan Antonio Castro-Flores

Rua Prof. Carolina Ribeiro, 30, ap. 91, Vila Mariana

04116-020 - São Paulo, SP, Brazil

E-mail: castroja@me.com 